\title{
Work Engagement, Intrinsic Motivation and Job Satisfaction among Employees of a Diamond Mining Company in Zimbabwe
}

\author{
Polite Masvaure, *Shaun Ruggunan, A. Maharaj \\ University of KwaZulu-Natal, Westville Campus, Durban, South Africa \\ *ruggunans@ukzn.ac.za
}

\begin{abstract}
This paper seeks to establish the relationships between three job characteristics constructs, namely work engagement, intrinsic motivation and job satisfaction in a workplace notorious for discord and conflict between workers and employers. A quantitative methodology was adopted using a crosssectional survey. Respondents were selected from the workers at a mining company, with a final sample of 156 employees participating in the study. The Utrecht Work Engagement Scale, Intrinsic Motivation Inventory and the Minnesota Job Satisfaction Questionnaire were used to collect data. The results of the study indicate positive relationships between job satisfaction, work engagement and intrinsic motivation among the workers. Age and marital status were found to be significant contributors to workers' job satisfaction, intrinsic motivation and work engagement. Implications of these results are that human resource interventions are required in order to deal with enhancing work engagement, intrinsic motivation and job satisfaction. Furthermore, the results indicate that intrinsic motivation and work engagement can enhance job satisfaction. The current study adds to the research pointing at job satisfaction as a promising underlying mechanism for employees' to be internally motivated and engaged at work.
\end{abstract}

Keywords: Work Engagement, Intrinsic Motivation, Job Satisfaction

\section{Introduction}

Intrinsic motivation has become an important phenomenon, especially when considering that anyone who is responsible for the supervision of employees engaged in work duties, needs to be aware that some people participate more out of interest in the task than others do. Thus, getting to know employees' interests helps management in job structuring as well as in assigning the right people to different project assignments. Intrinsic motivation is experienced when a person is moved to act for the 'fun' or challenge entailed rather than because of external pressures or rewards. Having intrinsically motivated employees can be the greatest asset for any organisation, especially management, since less supervision will be needed. In addition, such employees always deliver the best performance which, in turn, motivates them, whilst the organisation enjoys the best outcome. In as much as it is important to know how best to manage, monitor or govern organisational employees, having employees that are self-driven to do their work is more important. The implication of this for management studies is that there is a need to have more knowledge and understanding on how to get the best from employees. This can largely be achieved by knowing and understanding their interests. On the other hand, work engagement has also become an important aspect in that it has positive consequences for the organisation. Research conducted on work engagement has shown that highly engaged employees become more committed to the organisation, thus leading to "...increased job satisfaction, lower absenteeism and turnover rates, improved health and wellbeing, more extra-role behaviours, higher performance and a greater exhibition of personal initiatives, proactive behaviour and learning motivation" (Schaufeli \& Bakker, 2004).The study investigates how the company under study ensures that employees' needs and expectations are met as a way of retaining them. Work engagement, intrinsic motivation and job satisfaction - the three key drivers to the competitive advantage of an organisation - were correlated with employees' attitudes towards work. Thus, it is from such a need that this research aims to examine the levels of intrinsic motivation, work engagement and job satisfaction amongst the miners.

It is important to note that limited labor and business related research has been conducted in the context of diamond mining industry. It is hoped that the current study will make a valuable contribution to eradicating the dearth of such literature and provide a platform on which further research can be established. Despite the fact of it being thoroughly researched in other contexts, the review of literature has shown that job satisfaction and work engagement within the mining sector lacked attention, 
specifically the diamond mining industry. The same scenario has also been detected for intrinsic motivation, thus calling for the need to explore these constructs in a mining industry context. The study hopes to make a policy-driven human resources intervention to address issues around employees' welfare in an organisation. Investigating miners' levels of engagement, intrinsic motivation and satisfaction is crucial, especially to the discipline of Human Resources Management, since most studies have been focusing on white collar employees. This study explores levels and interrelationships between work engagement, intrinsic motivation and job satisfaction among employees across the hierarchy including shop floor workers. The objectives of the study are:

I) To investigate the relationship between work engagement, intrinsic motivation and job satisfaction amongst mine workers.

ii) To identify the contributing factors that impact on the level of worker engagement, job satisfaction and intrinsic motivation of mine workers.

\section{Literature Review}

Work Engagement: Significant empirical work exists on work engagement (Hakanen et al, 2006; Hakanen et al, 2008; Klusmann et al, 2008; Salanova, 2011). Most of this work is conducted in Europe or North America, with limited empirical work conducted in Africa. Nguwi's 2011 study represents one of the few studies that examine work engagement of Zimbabwean employees. The results of the study reflected that the majority (almost three quarters) of the Zimbabwean, economically active population have a low level of engagement in their work (Nguwi, 2011). Current trends in organisational psychology position work engagement as construct of positive organisational behaviour (POB) (Luthans, 2002; Bakker et al 2008). According to Luthans (2002, p.59), РОВ “...is the study and application of positively oriented human resource strengths and psychological capacities that can be measured, developed and effectively managed for performance improvement in today's workforce". Luthans' definition of РОВ reflects the need for a positive approach towards human resources as well as the need for theory building, research and practical solutions (Bakker et al., 2008).

Two different but related schools of thought exist on work engagement and both of them "...consider work engagement as a positive, work related state of wellbeing or fulfilment" (Baker et al., 2008). The first school of thought, whose proponents are Maslach and Lieter (1997), view engagement as a direct opposite of burnout and can be assessed by the opposite pattern of score on the three dimensions of the Maslach Burnout Inventory, which are exhaustion, cynicism and ineffectiveness. On the other hand, engagement is characterised by energy, involvement, and efficacy and in the situation of burnout, energy becomes exhaustion, involvement becomes cynicism and efficacy turns into ineffectiveness (Baker et al., 2008). The second school of thought, however, views work engagement as an autonomous concept which is negatively related to burnout. According to this school of thought, work engagement entails a positive, fulfilling, work related state of mind that is characterised by vigour, dedication and absorption (Bakker \& Demmerouti, 2008). Dedication refers to "...being strongly involved in one's work, and experiencing a sense of significance and enthusiasm" (Bakker \& Leiter, 2010, p. 156). The other dimension of work engagement is absorption and is characterised by being fully concentrated and happily immersed in one's work, whereby time passes quickly and one has difficulties with detaching oneself from work (Bakker \&Demmerouti, 2008). Thus, engaged employees, according to the second school of thought, feel strong and vigorous at work, enthusiastic about the work they do and are very often immersed in that work.

Work engagement has been found to be different from other psychological constructs like organisational commitment, job satisfaction and job involvement (Schaufeli, Leiter \& Maslach, 2009). For instance, organisational commitment defines an employee's loyalty to the organisation, but engagement focuses on the work itself (Storm \& Rothmann, 2003) and job satisfaction explains the extent to which work is a source of need fulfilment and contentment. Unlike engagement, job satisfaction does not encompass the employee's relationship with the work itself. Work engagement and 'workaholism' have also been differentiated in the literature. On one hand, engaged employees work hard (vigour), are involved (dedication) and feel happily engrossed (absorbed) in their work and may seem similar to workaholics, but are different in the sense that engaged workers lack the typical compulsive drive possessed by workaholics whose need to work is exaggerated to the point that it endangers their health, reducing happiness and interpersonal relations (Bakker et al., 2008). Through this distinction, one can conclude that there is a more positive contribution to the health status of an individual when they are engaged in their work than when they are workaholics. Work engagement, however, is closely related to the term 'flow', which represents a state of optimal experience that is characterised by focused attention, a clear 
mind and body unison, effortless concentration, complete control, loss of self-consciousness, distortion of time and intrinsic enjoyment (Csikszentmihayli, 1990). The difference between flow and engagement is that flow is more complex and refers more to a short-term experience, whereas engagement is a persistent state of mind (Storm \&Rothmann, 2003).

Drivers of work engagement: A positive relationship between work engagement and job resources has been consistently reported (Bakker \& Demerouti, 2008). These authors work from the premise that job resources play either an intrinsic motivational role because they foster employees' growth, learning and development, or an extrinsic motivational role because they are instrumental in achieving work goals. For the intrinsic motivation role job, resources fulfil basic human needs, such as the needs for autonomy, relatedness and competence (Ryan \& Frederick, 1997). The extrinsic motivational role played by job resources is through fostering the willingness to dedicate one's efforts and abilities to the work task (Meijman \& Mulder, 1998). Having a positive mind-set towards oneself predicts goal-setting, motivation, performance, job and life satisfaction, career ambition and other desirable outcomes suggesting a positive relationship between personal resources and work engagement (Judge \& Piccolo, 2004).

There are determinants and mediating effects of three psychological conditions, namely: meaningfulness, safety and availability - on employees' engagement in their work (May, Gilson \& Harter, 2004). Psychological meaningfulness is the value of a work goal or purpose, judged in relation to an individual's own ideals or standards (Van Zyl, Deacon \& Rothman, 2010). That is, the individual feels as though he or she is receiving a return on his or her self-investment in work, which provides physical, cognitive and emotional energies (Van Zyl et al., 2010). Thus, these energies in turn facilitate personal growth and motivation to work. The degree of meaningfulness is influenced by several factors, namely; characteristics of one's job, the value of a work goal or purpose, judged in relation to an individual's own ideals or standards (May, 2003) and personal growth. It has been found that a supportive relationship can foster perceptions of safety (Edmondson, 1999) and enhance employee creativity (Oldham \& Cummings, 1996). The ability of supervisors to put in place a supportive work environment will reflect concern for employees' needs and feelings, which will then help to solve work-related problems thus leading to the enhancement of employee self-determination, enjoyment and interest in their work (Deci \& Ryan, 1987). Psychological availability is an individual's belief that he or she has the physical, emotional or cognitive resources to engage the self at work (Stander \& Rothmann, 2010). Individuals are psychologically available to engage in their roles when they have positively assessed their ability to deal with both work and non-work aspects of their lives (Saks, 2006).

Intrinsic Motivation: Intrinsic motivation refers to the stimulation that drives an individual to adopt or change behaviour for his or her own internal satisfaction or fulfilment (Ryan \& Frederick, 1997). The current study is supported by Hunter's 2004 theory since it has given rise to major debates around intrinsic motivation. Hunter (2004), who is known mainly for her work in education, proposes a two-part system of motivation. In this model, Hunter does not specify individual motivators such as money or status, but instead, identifies two types of motivation namely; intrinsic and extrinsic motivation. Extrinsic motivation, according to Hunter, comprises five external factors that can be affected from the outside. These include: level of concern, success, feedback and interest and feeling tone.

Job satisfaction: Job satisfaction is defined as "...the extent to which people like or dislike their job" (Spector, 1997, p.2). Thus, job satisfaction implies an affective reaction towards a job. Hoppock (1935) defined job satisfaction as an outcome of psychological, environmental and physical circumstances combined together. The reasoning behind is that, if the expected outcomes are met, employees develop a positive emotional attachment to the organisation. This involves employees' appraisal of how well their jobs provide things that are viewed as important usually influenced by an employee's unique experiences, needs, values and expectations (Buitendach \& de Witte, 2005). It is important to note that, job satisfaction is a multifaceted construct that comprises both intrinsic and extrinsic job elements (Buitendach \& De Witte, 2005). Intrinsic elements of job satisfaction arise from rewards that are mediated internally. Extrinsic elements arise from rewards that are mediated externally (Mosadeghrad, Ferlie \& Rosenberg, 2008). External rewards refer to aspects that have little to do with work roles and internal rewards refer to work roles themselves (Buitendach \& De Witte, 2005). The former includes working conditions and pay, and the latter refers to factors such as skill utilisation and autonomy. Intrinsic determinants of job satisfaction pertain to the nature of and activities inherent to a set of tasks such as appreciation, feeling and intellectual stimulation (Herzberg, 1986). This is a subjective variable which is not always quantifiable but is experienced when employees fulfil the needs which they consider important in their 
work role. Job satisfaction, as a crucial aspect in an organisation, attracted a lot of research, with most studies being dominated by the person-environment fit paradigm (Mottaz, 1985). This implies that the greater the ability of a work environment to fulfil employees needs and demands, the higher the job satisfaction levels. The main criticism in the field of job satisfaction is based on the primary motive of research, which focuses on finding ways to maximise productivity by increasing employee satisfaction. In so doing, the values and personal needs of employees' can be taken for granted, leading to the exploitation of workers. Therefore, current and future research has been urged to create a balance between the needs and values of employers' and employees' job satisfaction (Saari \& Judge., 2004).

Antecedents of Job satisfaction: Personal determinants and organisational factors are two broad categories in which factors affecting job satisfaction can be grouped. Personal determinants of job satisfaction include race, gender, educational level, tenure, age and marital status (DeSantis \& Durst, 1996). The relationship between gender and job satisfaction has been extensively researched, yielding contradictory results (Kh. Metle, 2003). In the Murray \& Atkinson (1981) study it was found that females attach more importance to social factors, while males place greater value on pay, advancement and other extrinsic aspects". However, although these findings reveal a relationship between gender and job satisfaction, some studies failed to find the influence of gender on job satisfaction (e.g. Oshagbemi \& Gill, 2003). On the other hand, the majority of the studies which investigated the influence of educational level on job satisfaction revealed no consistent pattern (e.g. Crossman \& Abou-Zaki, 2003). However, in a similar study, Kh. Metle (2003) reported a strong relationship between educational level and job satisfaction. Research conducted on tenure and job satisfaction revealed a positive relationship (Bedeian, Ferris \& Kacmar, 1992) which is in contrast to Savery \& Duffy (1996) who found that longer tenure in a job may lead to boredom and lower levels of job satisfaction. In one of the studies, it was found that older employees are generally happier with the jobs than younger employees, while people who are more experienced in their jobs are more highly satisfied than those who are less experienced (Greenberg \& Baron, 2008). Marital status was found to be highly related to intrinsic and overall satisfaction (Kuo \& Chen, 2004).

\section{Methodology}

This quantitative study employed a cross-sectional survey utilising self-reported questionnaires to obtain information their perceptions of job satisfaction, worker engagement and intrinsic motivation. The study sampled 156 employees using stratified random sampling and investigations were conducted on the workforce as they appear in their respective work departments. Thus, strata were formed into departments from each of which participants were randomly selected (depending on their numbers), to complete the questionnaires. The response rate is acceptable as $77 \%$ of the population was accessed. The majority of the sample comprised males (78\%) compared with females $(20 \%)$ while $2 \%$ did not mention their gender status. Such trends prevailed because there were more males employed within the population females. In the study, the majority of the participants belonged to the age category of less than $25 y e a r s$ old, followed by the $25-35$ years group (56.37\%), 36-45 years $(25.16 \%), 46-55$ years $(8.5 \%)$ and $56+(3.2 \%)$. Therefore, it can be safely concluded that the majority of the sample used in the current study were younger participants, with a cumulative percentage of $56.37 \%$ of participants being less than 25 years. The majority of the participants were single (45\%), followed by married (44\%) divorced (3\%) and widowed (3\%).

Measuring instruments: Three standardised questionnaires and one biographical questionnaire that was developed by the researcherwere used. These include the Utrecht Work Engagement Survey (UWES), the Minnesota Satisfaction Questionnaire (MSQ) and the Intrinsic Motivation Inventory (IMI). The biographical data sheet gathered information on the participants' age, marital status, functional category, tenure and qualifications.

Utrecht Work Engagement Scale (UWES): Engagement levels of were measured using UWES. Within the definition of engagement are three concepts which include vigour, absorption and dedication (Schaufeli\& Bakker, 2004). Considerable research has been done on this instrument and reliability was found to be satisfactory. The UWES also has acceptable internal reliability with Cronbach alpha scores at 0.70 . According to Schaufeli and Bakker (2004), test-retest reliability indicated stability over time, as was evidenced by two longitudinal studies. Internal consistency and reliability for the three subscales of the UWES have been found to range between 0.68 and 0.91 (Coetzee \& Rothman, 2005). 
Intrinsic Motivation Inventory (IMI): The IMI is a multi-dimensional measurement device intended to assess participants' subjective experience related to a target activity in laboratory experiments (Butler, 1988). The instrument assesses participants' interest or enjoyment, perceived competence, effort, value/usefulness, felt pressure and tension, and perceived choice while performing a given activity, thus yielding six subscale scores. The IMI consists of varied numbers of items from these subscales, all of which have been shown to be factor-analytically coherent and stable across a variety of tasks, conditions and settings (McAuley, Duncan \& Tammen, 1989). The general criteria for inclusion of items on subscales have been a factor loading of at least 0.6 on the appropriate subscale, and no cross loadings above 0.4 . However, it is recommended that investigators need to perform their own factor analyses on new data sets (McAuley et al., 1989)

Minnesota Job Satisfaction Questionnaire (MSQ): The MSQ measures different areas that pertain to the job. Among others, aspects like autonomy, job variety, recognition and opportunity for promotion, the nature of work, and the work environment taps into the way company policies are put in place. In addition, the MSQ measures extrinsic job satisfaction (e.g. the chance to be a person of significance in the community) and intrinsic job satisfaction (e.g. the chance to do things that do not go against one's conscience). The alpha coefficients for the MSQ 20 range from 0.87 to 0.95 , which supports the internal consistency of the scale (Luthans \& Youssef, 2007).In addition, evidence for the validity of MSQ as a measure of general job satisfaction came from the test's performance according to theoretical expectation and from construct validation studies based on the theory of work adjustment (Weiss \& Cropanzano, 1996).

Table 1: Participants' Demographic Information

\begin{tabular}{|c|c|c|c|c|c|c|c|}
\hline Characteristic & Frequency & $\mathrm{N}$ & $\%$ & Characteristic & Frequency & $\mathrm{N}$ & $\%$ \\
\hline Gender & & & & Qualification & & & \\
\hline Male & 122 & 153 & 78.2 & Grade 10-12 & 125 & 142 & 80.1 \\
\hline Female & 31 & 153 & 19.9 & Certificate & 1 & 142 & 0.6 \\
\hline Age group & & & & Diploma & 8 & 142 & 5.1 \\
\hline$\leq 24$ & 61 & 153 & 39.1 & Degree & 5 & 142 & 3.2 \\
\hline $25-35$ & 56 & 153 & 35.9 & $\begin{array}{l}\text { Post-graduate } \\
\text { degree }\end{array}$ & 3 & 142 & 1.9 \\
\hline $36-45$ & 25 & 153 & 16.0 & Tenure & & & \\
\hline $46-55$ & 8 & 153 & 5.1 & $<5$ years & 122 & 137 & 78.2 \\
\hline Older than 56 & 3 & 153 & 1.9 & 6-10 years & 8 & 137 & 5.1 \\
\hline Race & & & & $11-20$ years & 4 & 137 & 2.6 \\
\hline $\begin{array}{l}\text { African } \\
\text { Marital Status }\end{array}$ & 151 & 151 & 96.8 & $\begin{array}{l}\text { More than } 20 \text { years } \\
\text { Position }\end{array}$ & 3 & 137 & 1.9 \\
\hline Single & 71 & 151 & 45.5 & Top-Level manager & 1 & 149 & 0.6 \\
\hline Divorced & 5 & 151 & 3.2 & Middle Level & 4 & 149 & 2.6 \\
\hline Widowed & 5 & 151 & 3.2 & Lower level & 8 & 149 & 5.1 \\
\hline Married & 70 & 151 & 44.9 & Administrator & 3 & 149 & 1.9 \\
\hline \multirow[t]{3}{*}{ Married } & 70 & 151 & 44.9 & Supervisor & 11 & 149 & 7.1 \\
\hline & & & & General employee & 121 & 149 & 77.6 \\
\hline & & & & Operator-Driver & 1 & 149 & 0.6 \\
\hline
\end{tabular}

Research procedure: The study protocol was approved by the University of KwaZulu Natal's Research Ethics Committee. This was followed by a pilot study, conducted to assess the effectiveness of the instruments in relation to aspects such as length, wording and validity. Permission to conduct the study was also sought from the Management of the mining company. The study used questionnaires to collect dataall participants gave their informed consent before participating in the study. The questionnaires were administered by the researcher with the assistance of three assistants from the Human Resources department, directly to participants after obtaining a sampling frame from the Human Resources Department which allowed the researcher to group the miners into different groups, such as functional categories. Other ethical considerations applied throughout the research process include confidentiality and withdrawal from the research process even after informed consent had been given, was allowed.

Statistical analysis: In the analysis of the obtained data, the SPSS version 21 (IBM SPSS Inc., 2012) and SAS version 9.2 were used. Factor Analysis was employed to identify the contributing factors for each employee's job satisfaction, intrinsic motivation and work engagement levels by reducing many items into smaller sets of underlying factors that summarise the major contributing factors affecting the three 
variables. Descriptive statistics that were used in this study included standard deviation, range and mean which provided a description of the data which then enhanced the understanding of the obtained data. To determine the reliability of the instruments used in the study, Cronbach's Alpha was conducted. To identify relationships on work engagement, intrinsic motivation and job satisfaction, Pearson's moment correlations were conducted. To identify the factors that play a significant role in determining job satisfaction, a work engagement and intrinsic motivation cumulative logistic regression model was used.

\section{Results}

Table 2: Cronbach's alpha Values

\begin{tabular}{|c|c|c|c|c|c|c|}
\hline Scale & $\chi^{2}$ & A & $\begin{array}{l}\text { Removing } \\
\text { items } \\
\text { increase } \alpha\end{array}$ & to & $\begin{array}{l}\text { Item's } \quad \text { with } \\
r<0.30\end{array}$ & Removed \\
\hline Work Engagement & 315.148 & 0.724 & 2 and 10 & & 2,10 and 14 & - \\
\hline Work Engagement* & 288.417 & 0.879 & 14 & & 14 & 2 and 10 \\
\hline Work Engagement.* & 206.299 & 0.886 & 13 & & - & 2,10 and 14 \\
\hline Intrinsic Motivation & 50.073 & 0.681 & 3 and 4 & & 3 & - \\
\hline Intrinsic Motivation* & 18.221 & 0.755 & 2 and 4 & & - & 3 \\
\hline Perceived Competence & 23.959 & 0.695 & 6 & & 6 & - \\
\hline $\begin{array}{l}\text { Perceived } \\
\text { Competence* }\end{array}$ & 10.442 & 0.862 & - & & - & 6 \\
\hline Eff/Importance & 37.29 & 0.816 & - & & - & - \\
\hline Press/tension & 6.435 & 0.681 & - & & - & - \\
\hline Perceived Choice & 108.301 & 0.589 & 3 and 6 & & 3 and 6 & \\
\hline Perceived Choice* & 11.24 & 0.771 & 1 & & - & 3 and 6 \\
\hline Relatedness & 106.691 & 0.791 & - & & - & \\
\hline Relatedness* & 3.00 & 0.823 & - & & - & $3,4,7$ \\
\hline Job Satisfaction & 425.692 & 0.576 & 5,9 and 11 & & 5,9 and 11 & - \\
\hline Job Satisfaction* & 346.597 & 0.902 & - & & - & 5,9 and 11 \\
\hline
\end{tabular}

* indicates the same scale as above but some items (indicated) were removed.

Factor Analysis: In order to determine the factor structure of UWES, IMI and MSQ, factor analysis was undertaken. A confirmatory factor analysis was performed using a maximum likelihood procedure with only one factor. Furthermore, an investigation of the correlation between each of these items and this latent factor was done. The literature suggests that one considers correlations between 0.3 and 0.9 as acceptable. Correlations that are near perfect might propose multi-collinearity. It was set that if the chisquared values are high then there might be a need to increase the minimum acceptable correlation to 0.4. Table 2 indicates each scale, the chi-square goodness of fit value, the value of Cronbach's alpha, the item/s on the scale that would increase the value of Cronbach's alpha if they were removed, the items on the scale that had a correlation $(r)$ of less than 0.3 with the factor of the scale, and the items that were removed from the analysis because of previous unreliability. For work engagement and job satisfaction, the chi-squared values were still very high even in the reduced models.

Table 3: Psychometric Characteristics of Instruments

\begin{tabular}{|c|c|c|c|c|c|c|c|}
\hline Variable & Minimum & Maximum & Mean & SD & Skewness & Kurtosis & $\alpha$ \\
\hline Work Engagement & 0 & 128 & 69.31 & 17.982 & -.854 & 2.756 & 0.89 \\
\hline Job Satisfaction & 0 & 100 & 71.04 & 18.016 & -1.881 & 4.216 & 0.90 \\
\hline $\begin{array}{l}\text { Intrinsic } \\
\text { Satisfaction }\end{array}$ & 12.00 & 107.00 & 46.5455 & 9.84565 & 2.222 & 15.791 & 0.54 \\
\hline $\begin{array}{ll}\text { Extrinsic } & \text { Job } \\
\text { Satisfaction } & \end{array}$ & 6.00 & 76.00 & 23.1357 & 6.84905 & 4.270 & 31.359 & 0.58 \\
\hline $\begin{array}{l}\text { Intrinsic } \\
\text { Motivation }\end{array}$ & 0 & 33 & 20.56 & 5.928 & -1.675 & 4.014 & 0.75 \\
\hline $\begin{array}{l}\text { Perceived } \\
\text { Competence }\end{array}$ & 0 & 28 & 19.74 & 4.723 & -1.296 & 2.803 & 0.86 \\
\hline Eff/Importance & 0 & 56 & 16.24 & 4.754 & 2.905 & 33.227 & 0.82 \\
\hline Pressure/tension & 0 & 17 & 11.73 & 2.865 & -1.997 & 6.587 & 0.68 \\
\hline Perceived Choice & 0 & 26 & 17.18 & 4.620 & -2.062 & 5.467 & 0.77 \\
\hline Relatedness & 0 & 31 & 19.11 & 5.271 & -2.084 & 5.964 & 0.82 \\
\hline
\end{tabular}


Descriptive Statistics: The descriptive statistics and alpha coefficients of the measuring instruments are reported in Table 2. Work engagement $(\mathrm{m}=69.31$; $\mathrm{SD}=17.98)$ reported the highest mean; and lowest mean $(\mathrm{m}=11.73 ; \mathrm{SD}=2.865)$ was reported for Pressure/tension. The Cronbach Alpha Coefficients ranged from 0.54 to 0.90 , thus indicating that the instruments were reliable. Work engagement showed best fit (without the loss of too many items) and a good (close to excellent) Cronbach's alpha (0.89) when items 2, 10 and 14 were removed. Perceived competence had a good fit and a Cronbach's alpha (0.86) when item 6 was removed. Effort/Importance had a reasonable fit and a good Cronbach's alpha (0.82) without the need to remove any of the items. Pressure/Tension had a reasonable fit and an average Cronbach's alpha (0.68). Perceived choice had an acceptable Cronbach's alpha (0.77) and showed a good fit between the items and the latent factor when items 3 and 6 were removed. Relatedness had a good Cronbach's alpha (0.82) and an extremely good fit when items 3, 4 and 7 were removed. Thus, overall intrinsic motivation had an acceptable Cronbach's alpha (0.76) and showed a good fit between the items and the latent factor, when item 3 was removed. Job satisfaction had an improved fit and an excellent Cronbach's alpha (0.90) when items 5, 9 and 11 were removed from the scale.

Table 4: Pearson Product-Moment Correlation Coefficients

\begin{tabular}{|c|c|c|c|c|c|c|c|}
\hline Variable & & Mean & SD & 1 & 2 & 3 & 4 \\
\hline 1. Work Engagement & & 69.31 & 17.98 & 1 & & & \\
\hline 2. Job Satisfaction & & 71.04 & 18.02 & $0.543^{* * *++}$ & 1 & & \\
\hline $\begin{array}{l}\text { 3.Intrinsic } \\
\text { Satisfaction }\end{array}$ & Job & 46.5455 & 9.846 & $0.380^{* * *_{+}}$ & $0.698^{* * *++}$ & 1 & \\
\hline $\begin{array}{l}\text { 4. Extrinsic } \\
\text { Satisfaction }\end{array}$ & Job & 23.1357 & 6.849 & 0.134 & $0.514^{* * *_{++}}$ & $0.215^{*}$ & 1 \\
\hline 5. Intrinsic Motivation & & 20.56 & 5.928 & $0.371^{* * *_{+}}$ & $0.399^{* * *_{+}}$ & $0.171^{*}$ & 0.129 \\
\hline
\end{tabular}

$* \mathrm{p} \leq 0.05$ - Statistically significant; ${ }^{* * *} \mathrm{p} \leq 0.001$ - Statistically significant; $+\mathrm{r}>0.30$ - Practically significant (medium effect); ++ r >0.50 - Practically significant (large effect)

Pearson's Moment Correlations: Pearson Product Moment correlation was calculated to assess the relationship between Job satisfaction, Work engagement and intrinsic motivation. As such the following hypotheses were tested:

Hypothesis 1: There is a significant relationship between job satisfaction and work engagement.

Hypothesis 2: There is a significant relationship between Job satisfaction and intrinsic motivation.

Hypothesis 3: there is a significant relationship between work engagement and intrinsic motivation.

As shown in Table 4, Job satisfaction and Work engagement were found to have a statistically and practically significant relationship, $r=0.543 ; n=156, p \leq 0.001$ (Large effect). Findings further indicated that Job satisfaction had a statistically significant relationship with Intrinsic motivation, $\mathrm{r}=-0.399, \mathrm{n}=$ 156, $\mathrm{p} \leq 0.001$ (medium effect). Work engagement had a practically (medium effect) and statistically significant relationship with Intrinsic Motivation, $r=0.371, n=156, p \leq 0.001$.

Table 5: Cumulative logistic regression modelling (Job Satisfaction)

\begin{tabular}{|c|c|c|c|c|c|c|c|}
\hline \multicolumn{8}{|c|}{ Analysis of Maximum Likelihood Estimates } \\
\hline Parameter & & DF & Estimate & $\begin{array}{l}\text { Standard } \\
\text { Error }\end{array}$ & $\begin{array}{l}\text { Wald } \\
\text { Square }\end{array}$ & Chi- & Pr $>$ ChiSq \\
\hline Intercept & 1 & 1 & -2.9245 & 2.6347 & 1.2321 & & 0.2670 \\
\hline Intercept & 3 & 1 & 1.0683 & 2.4885 & 0.1843 & & 0.6677 \\
\hline Intercept & 4 & 1 & 4.7945 & 2.5234 & 3.6100 & & 0.0574 \\
\hline GENDER & & 1 & 0.3398 & 0.5410 & 0.3946 & & 0.5299 \\
\hline AGE GROUP & & 1 & 0.1799 & 0.2736 & 0.4324 & & 0.5108 \\
\hline MARITAL STATUS & & 1 & 0.3532 & 0.1766 & 3.9996 & & $0.0455^{*}$ \\
\hline TENURE & & 1 & -0.1950 & 0.3582 & 0.2964 & & 0.5861 \\
\hline QUALIFICATION & & 1 & 0.2352 & 0.2162 & 1.1828 & & 0.2768 \\
\hline POSITION & & 1 & -0.0035 & 0.1975 & 0.0003 & & 0.9858 \\
\hline PC_MEAN & & 1 & -0.7906 & 0.2581 & 9.3836 & & $0.0022^{*}$ \\
\hline EI_MEAN & & 1 & -0.3150 & 0.2606 & 1.4619 & & 0.2266 \\
\hline PT_MEAN & & 1 & -0.0531 & 0.2600 & 0.0418 & & 0.8380 \\
\hline PCHOICE_MEAN & & 1 & -0.2374 & 0.2351 & 1.0202 & & 0.3125 \\
\hline REL_MEAN & & 1 & 0.3387 & 0.2545 & 1.7706 & & 0.1833 \\
\hline
\end{tabular}

${ }^{*} \mathrm{p} \leq 0.05$ - Statistically significant; ${ }^{* * *} \mathrm{p} \leq 0.001$ - Statistically significant 
Regression Analysis: A cumulative logistic regression model was applied to the data through the logistic procedure in SAS 9.2. The factors considered were: gender, age, marital status, tenure, highest education attained, position, perceived competence, effort/importance, pressure/tension, perceived choice and relatedness. Table 5 illustrates the findings on how each of these factors contributes to job satisfaction, work engagement and intrinsic motivation among the studied miners. From Table 5, it can be seen that Marital Status and Perceived Competence are significant at the 5\% level of significance, as indicated by the p-values 0.0455 and 0.0022 respectively (since $\mathrm{p}<0.05$ ). Further analysis of the probability graphs that reflected how changes in Marital Status and Perceived Competence respectively, would affect Job Satisfaction. Single employees had the greatest probability of experiencing higher levels of Job Satisfaction and that the higher the level of perceived competence, the higher the individuals' job satisfaction.

Table 6: Cumulative Logistic Regression Modelling (Work Engagement)

\begin{tabular}{|c|c|c|c|c|c|c|}
\hline \multicolumn{7}{|c|}{ Analysis of Maximum Likelihood Estimates } \\
\hline Parameter & & DF & Estimate & $\begin{array}{l}\text { Standard } \\
\text { Error }\end{array}$ & Wald Chi-Square & Pr $>$ ChiSq \\
\hline Intercept & 1 & 1 & -0.5950 & 2.4220 & 0.0604 & 0.8059 \\
\hline Intercept & 2 & 1 & 0.5633 & 2.2831 & 0.0609 & 0.8051 \\
\hline Intercept & 3 & 1 & 2.5793 & 2.2534 & 1.3102 & 0.2524 \\
\hline Intercept & 4 & 1 & 4.7924 & 2.2876 & 4.3887 & 0.0362 \\
\hline Intercept & 5 & 1 & 7.6548 & 2.3399 & 10.7022 & 0.0011 \\
\hline GENDER & & 1 & -0.1231 & 0.4858 & 0.0642 & 0.8000 \\
\hline AGE GROUP & & 1 & -0.0451 & 0.2479 & 0.0330 & 0.8558 \\
\hline MARITAL STATUS & & 1 & 0.1251 & 0.1557 & 0.6457 & 0.4217 \\
\hline TENURE & & 1 & -0.0531 & 0.3311 & 0.0257 & 0.8727 \\
\hline QUALIFICATION & & 1 & 0.3105 & 0.1986 & 2.4433 & 0.1180 \\
\hline POSITION & & 1 & 0.1588 & 0.1809 & 0.7708 & 0.3800 \\
\hline PC_MEAN & & 1 & -0.4926 & 0.2219 & 4.9277 & $0.0264^{*}$ \\
\hline EI_MEAN & & 1 & -0.6923 & 0.2397 & 8.3412 & $0.0039 *$ \\
\hline PT_MEAN & & 1 & -0.4339 & 0.2354 & 3.3971 & 0.0653 \\
\hline PCHOICE_MEAN & & 1 & -0.0583 & 0.2108 & 0.0765 & 0.7821 \\
\hline REL_MEAN & & 1 & -0.0208 & 0.2278 & 0.0084 & 0.9271 \\
\hline
\end{tabular}

$* \mathrm{p} \leq 0.05$ - Statistically significant; ${ }^{* * *} \mathrm{p} \leq 0.001$ - Statistically significant

Table 7: Cumulative logistic regression modelling (Intrinsic Motivation)

\begin{tabular}{|c|c|c|c|c|c|c|c|}
\hline \multicolumn{8}{|c|}{ Analysis of Maximum Likelihood Estimates } \\
\hline Parameter & & DF & Estimate & $\begin{array}{l}\text { Standard } \\
\text { Error }\end{array}$ & $\begin{array}{l}\text { Wald } \\
\text { Square }\end{array}$ & Chi- & Pr>ChiSq \\
\hline Intercept & 1 & 1 & 5.4276 & 2.5285 & 4.6079 & & 0.0318 \\
\hline Intercept & 2 & 1 & 7.6146 & 2.5494 & 8.9208 & & 0.0028 \\
\hline Intercept & 3 & 1 & 10.2629 & 2.6440 & 15.0662 & & 0.0001 \\
\hline Intercept & 4 & 1 & 14.3458 & 2.7879 & 26.4789 & & $<.0001$ \\
\hline GENDER & & 1 & -0.5457 & 0.5360 & 1.0364 & & 0.3087 \\
\hline AGE GROUP & & 1 & -0.3764 & 0.2678 & 1.9751 & & 0.1599 \\
\hline MARITAL STATUS & & 1 & 0.2621 & 0.1677 & 2.4429 & & 0.1181 \\
\hline TENURE & & 1 & -0.1263 & 0.3765 & 0.1126 & & 0.7372 \\
\hline QUALIFICATION & & 1 & 0.0673 & 0.2177 & 0.0957 & & 0.7571 \\
\hline POSITION & & 1 & -0.0261 & 0.2004 & 0.0169 & & 0.8964 \\
\hline PC_MEAN & & 1 & -1.2167 & 0.2598 & 21.9351 & & $<.0001^{* * *}$ \\
\hline EI_MEAN & & 1 & -0.8575 & 0.2595 & 10.9162 & & $0.0010^{* *}$ \\
\hline PT_MEAN & & 1 & -0.5238 & 0.2591 & 4.0882 & & $0.0432^{*}$ \\
\hline PCHOICE_MEAN & & 1 & -0.4627 & 0.2321 & 3.9762 & & $0.0461^{*}$ \\
\hline REL_MEAN & & 1 & 0.4020 & 0.2463 & 2.6638 & & 0.1027 \\
\hline
\end{tabular}

${ }^{*} \mathrm{p} \leq 0.05$ - Statistically significant; ${ }^{* *} \mathrm{p} \leq 0.01$ - Statistically significant; ${ }^{* * *} \mathrm{p} \leq 0.001$ - Statistically significant

As shown in Table 6, Perceived Competence and Effort/Importance were statistically significant $\mathrm{p}=0.0264$ and $\mathrm{p}=0.0039$ (at level $\mathrm{p}<0.05$ ) respectively. The probability graphs reflect how changes in Perceived Competence, Effort/Importance and Pressure/Tension respectively, would affect Work 
Engagement. Results indicated that the greatest probability of higher work engagement is when Perceived Competence is at a level 2 or 4 and a higher level of Effort/Importance would result in higher levels of work engagement. A distinct trend was also revealed: a higher rank of pressure/tension indicates a higher level of work engagement. It should be noted that a higher rank of pressure/tension is actually indicative of a lower amount of pressure/tension that is felt by an individual. This implies that an individual who feels less pressure/tension will have a higher level of work engagement. The output of the cumulative logistic regression modelling shown in Table 7 indicates that Perceived Competence, Effort/Importance, Pressure/Tension and Perceived Choice contribute significantly to Intrinsic motivation as indicated by the $\mathrm{p}=0.0001, \mathrm{p}=0.001, \mathrm{p}=0.0432$ and $\mathrm{p}=0.0461$ respectively. Further analysis of the probability graphs indicated that, the higher the level of Perceived Competence, the greater the probability that Intrinsic Motivation is higher. The same was found for Effort/Importance, pressure/tension. However it should be noted that; a higher ranking of pressure/tension is actually indicative of a lower amount of pressure/tension felt by an individual. This implies that an individual who feels less pressure/tension will have a higher level of intrinsic motivation. It should be noted that a lower level of perceived choice is indicative of an individual exercising more choice in their job.

Discussion: The objective of this study was to determine levels of work engagement, intrinsic motivation and job satisfaction among miners of a diamond mining company in Zimbabwe. Therefore, the study examined levels and interrelationships between three constructs: work engagement, intrinsic motivation and job satisfaction among mine workers in a diamond mining company in Zimbabwe. The majority of employees in this study were males $(78 \%)$. Such gender representation echoes the assumption that work is primarily the domain of men and home the domain of women, such that the two spheres are not connected. This, in a way affects working practices and family roles. Such trends have dominated the diamond industry, where males continue to dominate. It is interesting to find that the percentage of employees who are married in this company is almost the same as the percentage of employees who are single, $44 \%$ and $45 \%$ respectively. Marital status has been found to have an influence on an individual's work. For instance, in one of the studies conducted, it was found that family resources, such as support from spouse, may also be relevant and influence work engagement (Bakker et al., 2008). A confirmatory factor analysis was performed using a maximum likelihood procedure with only one factor. To try and increase the reliability of the scale, successive reduction of items was computed on the scales, removing items on the scale that had a correlation $(r)$ of less than 0.3 work engagement and job satisfaction had high chi-square values even in the reduced models. This indicates that the model did not fit too greatly to a single factor. There might be two or more factors that could explain more of the variation in the item responses. The problem in using two or more factors is that these factors would be orthogonal to each other (i.e. they would not be related). The analysis was continued, keeping in mind that work engagement and job satisfaction did not have the greatest fit when being used as a single factor.

The Cronbach Alpha Coefficients of the scales and subscales ranged from 0.54 to 0.90 , thus indicating that the measurement instruments were reliable. Stander and Rothmann (2010) have also demonstrated that instruments such as the UWES is valid for work done in the South African context, with high levels of internal consistency of the scale items: vigour: 0.79; dedication: 0.89; and absorption: 0.78 (Storm \&Rothmann, 2003).The study results revealed a significant relationship between job satisfaction and work engagement as well as between job satisfaction and intrinsic motivation. Furthermore, the tests revealed that intrinsic motivation and work engagement can enhance job satisfaction. This implies a positive contribution of the three constructs to efficiency and effectiveness in an organisation In support of the above findings, a study conducted in a surface coatings manufacturing organisation in South Africa revealed a statistically significant positive correlation between intrinsic motivation and work engagement (practically significant, medium effect) and meaning, correlated positively (practically significant, medium effect) with intrinsic motivation and work engagement (May, Gilson \& Harter, 2004). Extrinsic motivation correlated significantly (large effect) with work engagement. The results showed that employees in this company were moderately intrinsically motivated. Such a state is not very good from a business perspective since it reflects that managers in this company are working with assumptions which could have detrimental effects on organisational relations and ultimately the performance of the organisation. In assessments of intrinsic motivation, negative responses were recorded on relatedness which encompassed the relationship between a manager (supervisor) and an employee.

The results clearly indicated poor relations. However, past research has shown that employees should always be treated with respect and it is the company's obligation to see that individual managers do not abuse their power or mistreat their subordinates (Josephson, Heijbel, Voss Afredsson \& Vingard, 2008). 
On the other hand, employees also have a moral obligation to the organisation, workmates and other organisational stakeholders. The moral obligations of an employee include loyalty, candour, caring and respect (Josephson et al., 2008). Given these two propositions by Josephson and colleagues, a healthy relationship is developed. Apart from the provision of training, the findings revealed that intrinsic motivation has to come from the individual and that the best way for it to be experienced is through liking what you are doing and believing in oneself. Such a finding is very interesting given the understanding that intrinsic motivation entails an inner drive to do something which comes from having an interest in something. Thus, self-efficacy was found to be important in the enhancement of intrinsic motivation.

\section{Conclusion and Implications}

Although being a new aspect in psychology, falling under the positive psychology realm, work engagement has proved to be crucial for an organisation's survival. Tracing the history of most businesses' major concerns and the reasons behind the failure of organisations, it is indisputable that focusing on engagement levels of employees in their work is a way forward. Although focus has been put on the conceptualisation of work engagement, there is a feeling of injustice to the aspect by ignoring the understanding of the concept within the mining industry. The diamond industry and more specifically the Zimbabwean context need more attention. Understanding work engagement within the diamond mining industry in Zimbabwe can go a long way in addressing the possible challenge of unhealthy employeremployee relations resulting from inadequate employee motivation and satisfaction, which contribute to employees' not fully applying themselves to work. This ultimately leads to organisational inefficiency and ineffectiveness, a situation which management does not hope for. Be that as it may, the ability of an organisation to have a broader understanding of work engagement as a concept, the contributing factors to it as well as knowing the consequences aligned with work engagement, is the greatest asset an organisation can have, if major organisational resources (employees) are to be fully utilised. As has been shown in the results, miners are averagely engaged which calls for management to look into ways in which the situation can be improved.

The following are the recommendations that have been submitted to the organisation: It is important for the managers in the company to have an in-depth understanding of their employees, especially regarding employees' welfare. This comes after the realisation that most managers in the company under study are working with inaccurate assumptions of what they think their employees prefer when at work. A scenario where there is no incorporation of employee concerns or preferences is a threat to the human resources approach which advocates a balance between organisational objectives and employee objectives, which may result in organisational ineffectiveness. It is crucial for management to design a flexible organisational structure which allows for an interactive communication style so as to enable shop floor employees to express their concerns to management. This will help in providing information on important aspects that an organisation may need to address. Thus, through having such structures in place, a platform to understand human resources-related problems will be created. Having knowledge of the business's internal, environmental human resources issues, allows the human resources managers of the company to deal amicably with any issues affecting the function. Having a working environment which takes into account social structures that facilitate informal activities among employees is crucial for improved employee performance. Through these informal structures, a lot of employee-related matters can be resolved since it opens up a space for communication among employees. Considering that lack of social activities (informal activities) have been a worrying issue to the majority of employees in the company, this could explain why employees in the company are averagely intrinsically motivated and engaged in their company. Hence, this calls for management to give a closer look at this issue. Managers need to equip themselves with knowledge and skills of broader issues to understand individual employees in an organisation. Having a rich knowledge base will equip human resources managers with strategies and proper interventions to deal with any employee-related issues.

Limitations of the study: Studies of the aspects of work engagement, job satisfaction and intrinsic motivation in one company in a mining sector have been rare, hence the reason for carrying out the current study. However, there are some limitations associated with the current study. For instance, the study is limited to one company which leads to issues of generalizability. Also important to note is the fact that diamonds were discovered recently at Marange in Zimbabwe and diamond mining has become a sensitive issue. This raises the probability that workers could be coached or be selective with the information they give to outsiders, thus only providing a partial view of factors that contribute to work engagement. 
Recommendations for future research: Considering that this is the first study on work engagement, intrinsic motivation and job satisfaction in a diamond mining context. It will be important to investigate these aspects on a larger scale (to include other mining companies) so as to have an in-depth understanding of these constructs holistically. Doing so will allow generalisability of the findings to the mining industry as a whole, which is something which cannot be done with the current study. There is a lot of contestation and controversy surrounding mining of diamonds in Zimbabwe, particularly on the Marange fields. Firstly, there is embargo on global marketing and free selling of Marange diamonds in the world. Secondly, the volatile political situation currently obtaining in the country may cause uncertainty for what the future holds for the miners in terms of job security. A study into how this psychologically affects the miners and what impact this may have on their levels of engagement, satisfaction and motivation is recommended.

\section{References}

Bakker, A. B. \& Demerouti, E. (2008). Towards a model of work engagement. Career Development International, 13, 209-223.

Bakker, A. B., Schaufeli, W. B., Leiter, M. P. \& Taris, T. W. (2008). Work engagement: An emerging concept in occupational health psychology. Work \& Stress, 22(3), 187-200.

Bakker, A. B. \& Leiter, M. P. (2010). Work engagement: A handbook of essential theory and research. New York, NY: Psychology Press.

Bedeian, A. G., Ferris, G. R. \& Kacmar, K. M. (1992). Age, tenure, and job satisfaction: A tale of two perspectives. Journal of Vocational Behavior, 40(1), 33-48.

Buitendach, J. \& De Witte, H. (2005). Job insecurity, extrinsic and intrinsic job satisfaction and affective organizational commitment of maintenance workers in a parastatal. South African Journal of Business Management, 36(2), 27-37.

Butler, R. (1988). Enhancing And Undermining Intrinsic Motivation: The Effects of Task-Involving and Ego-Involving Evaluation on Interest And Performance. British Journal of Educational Psychology, $58,1-14$.

Coetzee, S. E. \& Rothmann, S. (2005). Work Engagement of employees at a higher education institution in South Africa. Southern African Business Review, 9, 23-34.

Crossman, A. \& Abou-Zaki, B. (2003). Job satisfaction and employee performance of Lebanese banking staff, Journal of Managerial Psychology, 18(4), 368-376.

Csikszentmihalyi, M. (1990). Flow: The psychology of optimal experience. New York, NY: Harper \& Row Publishers, Inc.

Deci, E. L. \& Ryan, R. M. (1987).The support of autonomy and the control of behavior. Journal of Personality and Social Psychology, 53(6), 1024.

DeSantis, V. S. \& Durst, S. L. (1996).Comparing job satisfaction among public-and private-sector employees. The American Review of Public Administration, 26(3), 327-343.

Edmondson, A. (1999). Psychological safety and learning behavior in work teams. Administrative Science Quarterly, 44(2), 350-383.

Greenberg, J. \& Baron, R. A. (2008).Behavior in organizations. Upper Saddle River, NJ.

Hakanen, J. J., Bakker, A. B. \& Schaufeli, W. B. (2006). Burnout and work engagement among teachers. Journal of School Psychology, 43(6), 495-513.

Hakanen, J. J., Schaufeli, W. B. \& Ahola, K. (2008). The job demands-resources model: A three-year crosslagged study of burnout, depression, commitment, and work engagement. Work \& Stress, 22(3), 224-241.

Herzberg, F. (1986). One more time: How do you motivate employees? The Leader-Manager, 433.

Hoppock, R. (1935). Job satisfaction. London and New York: Harper and Brothers

Hunter, J. (2004). The world's most powerful leadership principle: How to become a servant leader. New York, NY: Crown Publishing Group

Josephson, M., Lindberg, P., Voss, M., Afredsson, L. \& Vingard, E. (2008). The same factors influence job turnover and long spells of sick leave. A 3-year follow-up of Swedish nurses. European Journal of Public Health, 18(4), 380-385.

Judge, T. A. \& Piccolo, R. F. (2004). Transformational and transactional leadership: A meta-analytic test of their relative validity. Journal of Applied Psychology, 89(5), 755.

Kh-Metle, M. (2003).The impact of education on attitudes of female government employees", Journal of Management Development, 22(7), 603 - 626.

Klusmann, U., Kunter, M., Trautwein, U., Lüdtke, O. \& Baumert, J. (2008). Engagement and emotional exhaustion in teachers: Does the school context make a difference? Applied Psychology: An International Review, 57, 127-151. 
Kuo, Y. F. \& Chen, L. S. (2004). Individual demographic differences and job satisfaction among information technology personnel: An empirical study in Taiwan. International Journal of Management, 21, 221-231.

Luthans, F. (2002). Psychological capital: Implications for HRD, retrospective analysis, and future directions. Human Resource Development Quarterly, 23(1), 1-8.

Luthans, F. \& Youssef, C. M. (2007).Emerging positive organizational behavior. Journal of Management, 33, 321-349.

Maslach, C. \& Leiter, M. P. (1997). The truth about burnout: How organizations cause personal stress and what to do about it. Jossey-Bass.

May, D. R. (2003). Fostering the human spirit at work: Toward an understanding of the influences on employees' experienced meaningfulness at work. Unpublished manuscript

May, D. R., Gilson, R. L. \& Harter, L. M. (2004).The psychological conditions of meaningfulness, safety and availability and the engagement of the human spirit at work. Journal of Occupational and Organizational Psychology, 77(1), 11-37.

McAuley, E., Duncan, T. \& Tammen, V. V. (1989). Psychometric properties of the Intrinsic Motivation Inventory in a competitive sport setting: A confirmatory factor analysis. Research Quarterly for Exercise and Sport, 60, 48-58.

Meijman, T. F. \& Mulder, G. (1998).Psychological aspects of workload. Handbook of Work and Organizational Psychology: Work Psychology, 2, 5-33.

Mosadeghrad, A. M., Ferlie, E. \& Rosenberg, D. (2008). A study of the relationship between job satisfaction, organizational commitment and turnover intention among hospital employees. Health Services Management Research, 21(4), 211-227.

Mottaz, C. J. (1985). The relative importance of Intrinsic and extrinsic rewards as determinants of work satisfaction. The Sociological Quarterly, 26(3), 365-385.

Murray, M. \& Atkinson, T. (1981).Gender differences in job satisfaction. Canadian Journal of Behavioural Research, 13, 44-52.

Nguwi, M. (2011). Work Engagement Trends in Zimbabwe. Financial Gazette http://allafrica.com/stories/201012220113.html Accessed 5 February 2014.

Oldham, G. R. \& Cummings, A. (1996). Employee Creativity: Personal and Contextual Factors at Work. The Academy of Management Journal, 39(3), 607-634.

Oshagbemi, T. \& Gill, R. (2003).Gender differences and similarities in the leadership styles and behavior of UK managers. Women in Management Review, 18(6), 288-298.

Ryan, R. M. \& Frederick, C. (1997). On energy, personality, and health: Subjective vitality as a dynamic reflection of well-being. Journal of Personality, 65(3), 529-565.

Saari, L. M. \& Judge, T. A. (2004).Employee attitudes and job satisfaction. Human Resource Management, 43(4), 395-407.

Saks, A. M. (2006). Antecedents and consequences of employee engagement. Journal of Managerial Psychology, 21, 600-619.

Salanova, M., Llorens, S. \& Schaufeli, W. B. (2011). Yes, I Can, I Feel Good, and I Just Do It! On Gain Cycles and Spirals of Efficacy Beliefs, Affect, and Engagement. Applied Psychology: An International Review, 60, 255-285

Savery, J. R. \& Duffy, T. M. (1996). Problem based learning: An instructional model and its constructivist framework. Constructivist Learning Environments: Case Studies in Instructional Design, 135-148.

Schaufeli, W. B. \& Bakker, A. B. (2004). Job demands, job resources, and their relationship with burnout and engagement: A multi-sample study. Journal of Organizational Behavior, 25(3), 293-315.

Schaufeli, W. B., Leiter, M. P. \& Maslach, C. (2009). Burnout: 35 years of research and practice. Career Development International, 14(3), 204-220.

Spector, P. E. (1997). Job satisfaction: Application, assessment, cause, and consequences: Sage.

Stander, M. W. \& Rothmann, S. (2010). Psychological empowerment, job insecurity, and employee engagement. SA Journal of Industrial Psychology, 36(1), 1-8.

Storm, K. \& Rothmann, S. (2003). A psychometric analysis of the Maslach Burnout Inventory-general survey in the South African police service. South African Journal of Psychology, 2, 175 -182

Van Zyl, L. E., Deacon, E. \& Rothmann, S. (2010). Towards happiness: Experiences of work-role fit, meaningfulness and work engagement of industrial/organisational psychologists in South Africa. South African Journal of Industrial Psychology, 36(1), 1-8.

Weiss, H. M. \& Cropanzano, R. (1996). Affective events theory: A theoretical discussion of the structure, causes and consequences of affective experiences at work. Research in Organizational Behavior, $18,1-74$ 